\title{
Probability analysis of an embedded water tank
}

\author{
Katarína Tvrdá ${ }^{1, *}$ \\ ${ }^{1}$ Slovak University of Technology in Bratislava, Faculty of Civil Engineering, Department of \\ Structural Mechanics, Radlinského 11, SK-810 05 Bratislava, Slovakia
}

\begin{abstract}
The design of building structures must fulfil specific regulations, in our case, different building standards, among them Eurocodes. In addition to deterministic procedures in structural design, these standards also allow probabilistic procedures. The embedded tank loaded with soil and liquid is solved by the probability analysis using ANSYS, which contains several probabilistic methods. The reinforced concrete tank is solved by the RSM probabilistic method, which uses the well-known Monte-Carlo method in the background. Input parameters (material properties of soil and reinforced concrete, load - pressure from water, geometric data - change of both wall and tank bottom thickness) are entered into the calculation with certain aberrances allowed by standards in the construction and loading of structures. The results are also sets of probabilistic variables with a certain variance, as opposed to a deterministic calculation, where only one value results. These procedures, which use statistical methods, have been at the forefront in recent decades. At the end of the paper, some results of the analysis of embedded reinforced concrete water tank (deterministic and probabilistic procedure) in state of tank failure on the second limit state are presented.
\end{abstract}

\section{Introduction}

Each structure shall be designed and constructed in such a way as to serve the intended purpose and to withstand any loads and influences which may arise during its intended life. The design of each structure shall meet the requirements for load-bearing capacity, serviceability and durability laid down in the relevant national standards and Eurocodes. The design and assessment of the structure can be made by a deterministic and probabilistic approach. The required reliability is achieved by design according to EN 1990 - EN 1999 and by appropriate design and management quality.

Current advances in computing technics and the widespread availability of information technology have led to the assumption of wider use of the probabilistic approach to assess the reliability of structures using various simulation methods.

A number of papers have been published on the probabilistic approach to structural assessment and structural reliability [1-6].

\footnotetext{
* Corresponding author: katarina.tvrda@stuba.sk
} 


\section{Deterministic tank analysis}

The storage tank built in Slovakia will be subjected to deterministic and probabilistic analysis. The cylindrical tank is fully embedded in the subsoil. It is made of reinforced concrete and is used for water storage.

The tank is made of concrete C 30-37. The outer diameter of the tank is $20 \mathrm{~m}$, the total height of the tank is $3 \mathrm{~m}$, the bottom thickness of the tank is $0.6 \mathrm{~m}$, and the thickness of the jacket is $0.5 \mathrm{~m}$. The subsoil consists of soil S3, sand with admixture of fine-grained soil, moderately facilitated.

The material properties of the concrete are considered as follows: modulus of elasticity of concrete of $30 \mathrm{GPa}$, Poisson number of 0.2 , volume gravity of $25 \mathrm{kN} / \mathrm{m}^{3}$. The material properties of the subsoil are: modulus of elasticity of $15 \mathrm{MPa}$ and Poisson number of 0.3. The static model of the cylindrical tank was created in Ansys [7] using elements Solid 185.

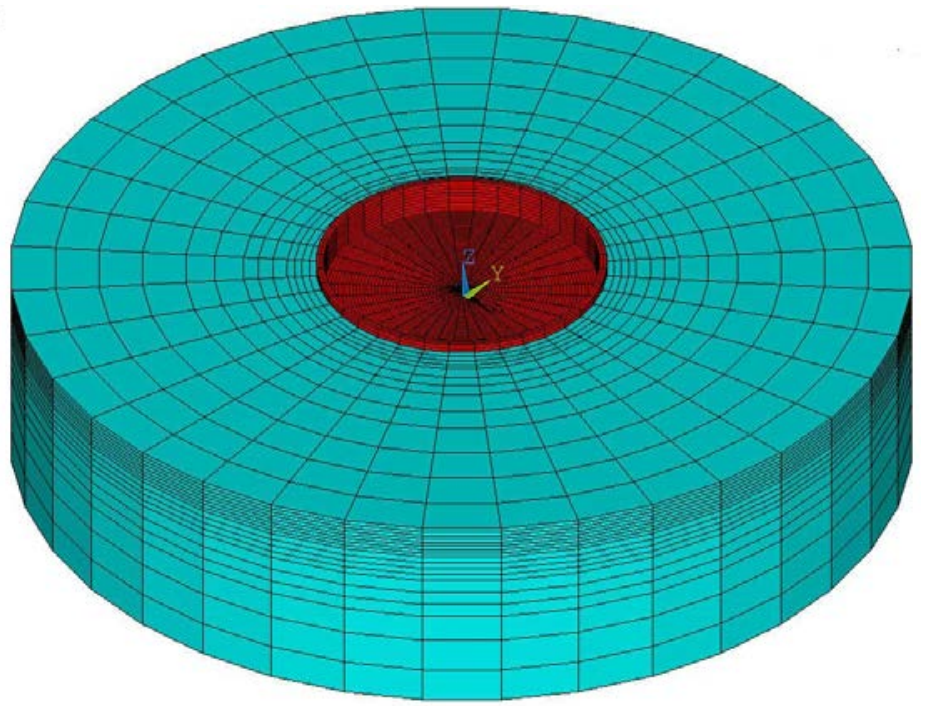

Fig. 1. Static model of subsoil mass with cylindrical tank.
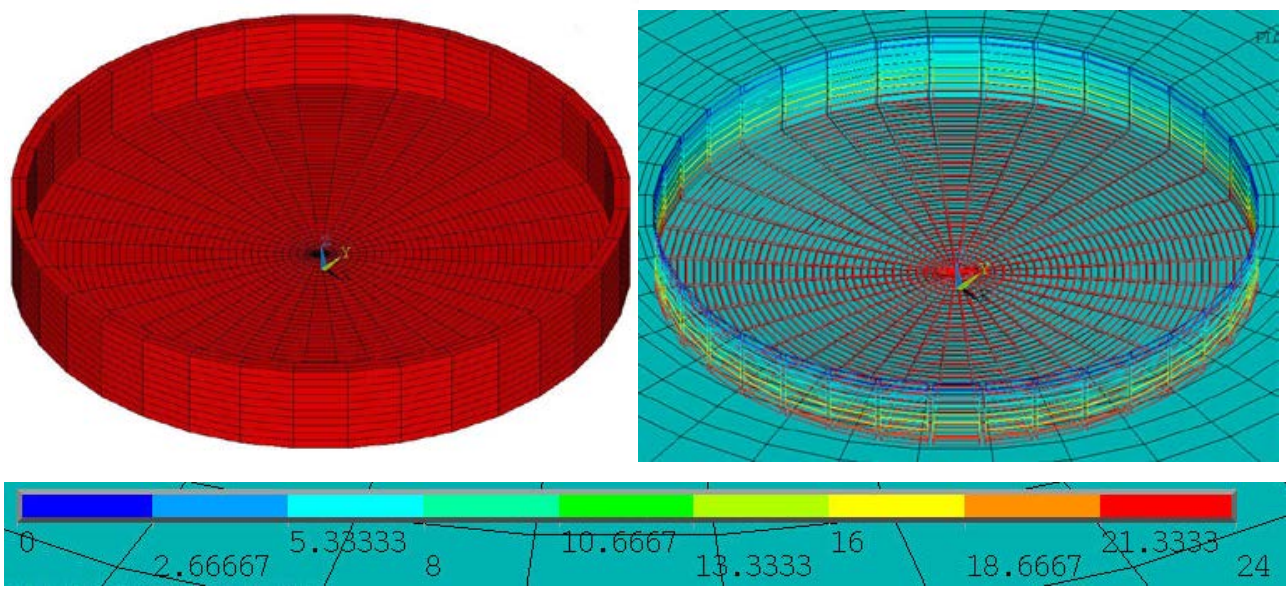

Fig. 2. Detail of the cylindrical tank (left) and the hydrostatic pressure load (right). 
From the deterministic calculation, the maximum deflection in the tank footing bottom was $19.73 \mathrm{~mm}$ and the minimum $15.15 \mathrm{~mm}$. The results of the static analysis are shown in the following figures. The maximum equivalent stress on the elements in the tank footing bottom was $2394.44 \mathrm{kPa}$ and the minimum $634.58 \mathrm{kPa}$. The diagram of vertical displacements on the whole model is shown in Fig.3.

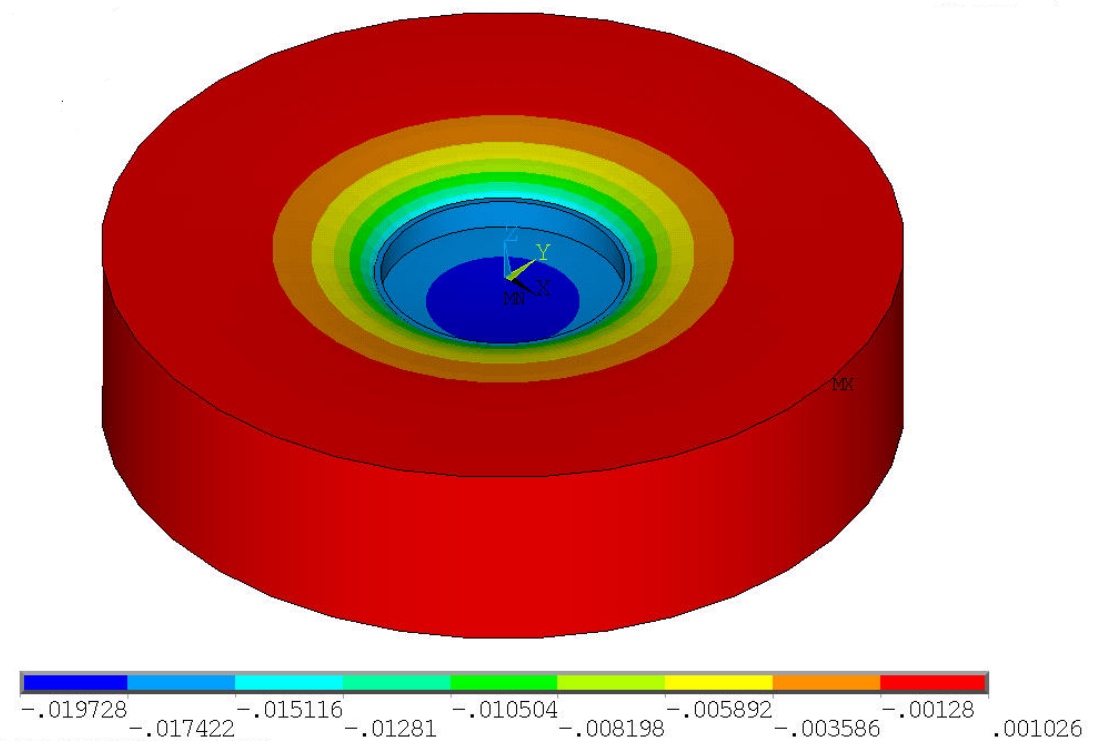

Fig. 3. The diagram of vertical displacements.

\section{Reliability analyses}

In the case of reliability analysis of structures, a probabilistic approach is used. Randomness in the loading, variability in materials and in geometrics of structures as well as inaccuracies in the model compared to reality can be included in the structural probability calculation. For this purpose, various methods for assessing the reliability have been developed.

At present it is possible to do probabilistic calculations even for complicated structures in programs based on stiffness variant of FEM.

\subsection{Reliability Criteria}

In the case of probabilistic approach, the measure of reliability should by identified with the survival probability

$$
P_{s}=1-P_{f},
$$

where $P_{\mathrm{f}}$ is the failure probability for the considered failure mode and within an appropriate period. The structure should be considered to be unsafe in the case when the calculated failure probability is larger than a present target value.

The measure of reliability depends on the lifetime of the structure and it is defined by the reliability index $\beta$ (Tab. 1). 
Table 1. Probability and reliability index by STN EN 1990 [8].

\begin{tabular}{|c|c|c|}
\hline \multirow{2}{*}{ Limit state } & \multicolumn{2}{|c|}{ Reliability index $\boldsymbol{\beta}$} \\
\cline { 2 - 3 } & $\mathbf{1}$ years & $\mathbf{5 0}$ years \\
\hline ultimate & $4.7\left(P_{\mathrm{f}} \approx 10^{-6}\right)$ & $3.8\left(P_{\mathrm{f}} \approx 10^{-4}\right)$ \\
\hline fatigue & - & $1.5-3.8\left(P_{\mathrm{f}} \approx 10^{-1}-10^{-4}\right)$ \\
\hline serviceability & $3.0\left(P_{\mathrm{f}} \approx 10^{-3}\right)$ & $1.5\left(P_{\mathrm{f}} \approx 10^{-1}\right)$ \\
\hline
\end{tabular}

\subsection{Uncertainties of input parameters in probability analysis}

The effect of the interaction of the structure with the subsoil can be introduced into probabilistic analysis through variability of the input data of the structure and the subsoil.

The variability of the material properties of the soil is defined by the modulus of elasticity of the soil E_z from geological measurements and by the variable Evar_z. The stiffness of the reinforced concrete tank is determined through the characteristic value of the Young's modulus E_c and the variable Evar_c.

The load is determined by the characteristic value q_v and the variable qvar_v. These input parameters are described in more detail in Tab. 2.

Table 2. Random input variable specification.

\begin{tabular}{|c|c|c|c|c|c|c|c|}
\hline $\begin{array}{c}\text { Charact. } \\
\text { value }\end{array}$ & value & $\begin{array}{c}\text { Variable } \\
\text { parameter }\end{array}$ & Histogram & $\begin{array}{c}\text { Mean } \\
\text { value }\end{array}$ & $\begin{array}{c}\text { Stand. } \\
\text { deviation }\end{array}$ & $\begin{array}{c}\text { Min. } \\
\text { value }\end{array}$ & $\begin{array}{c}\text { Max. } \\
\text { value }\end{array}$ \\
\hline E_z & $30 \mathrm{GPa}$ & Evar_z & normal & 1 & 0.05 & 0.828 & 1.195 \\
\hline E_c & $15 \mathrm{MPa}$ & Evar_c & normal & 1 & 0.04 & 0.873 & 1.136 \\
\hline q_v & $0-24$ & qvar_v & lognormal & 1 & 0.1 & 0.736 & 1.349 \\
\hline
\end{tabular}

The diagram of some input parameters can be seen in Fig. 4.
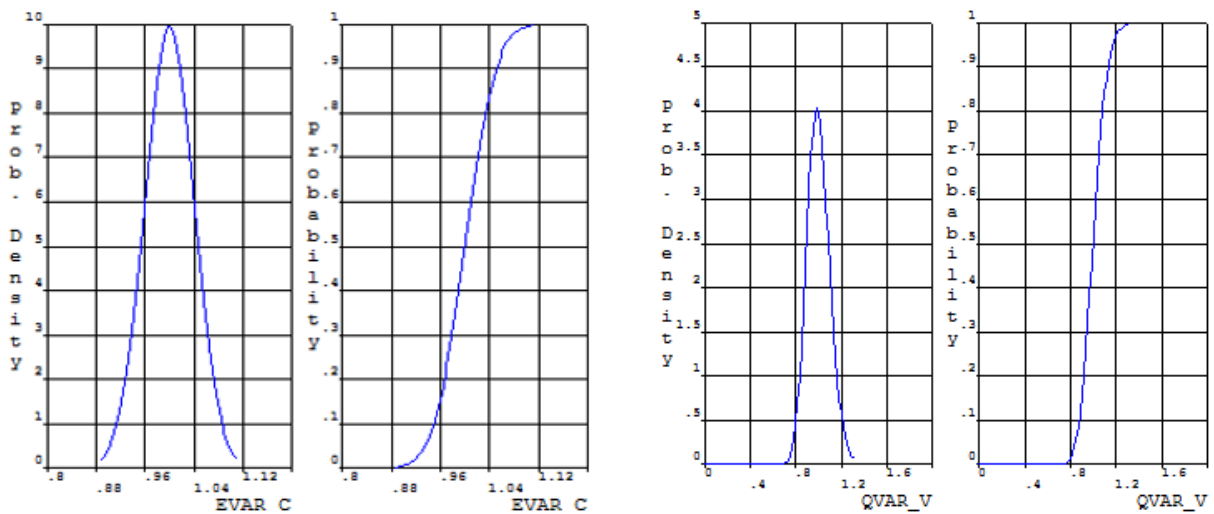

Fig. 4. The diagrams of Evar_c and Qvar_c.

\subsection{Reliability criteria for serviceability}

Reliability assessment of the embedded water tank is realized in accordance of the Eurocode and national standard requirements (1-5) for serviceability an ultimate limit state. The serviceability of this structure is limited by maximum vertical displacement and rotation. 
The function of structural failure in case of structural settlement is defined by the following relation:

$$
g(w)=1-w_{\mathrm{E}} / w_{\mathrm{R}} \geq 0,
$$

where $w_{\mathrm{E}}$ is the maximum displacement in vertical direction and $w_{\mathrm{R}}$ is the limit displacement.

The function of structural failure in case of structural rotation is:

$$
g(w)=1-f i_{\mathrm{E}} / f i_{\mathrm{R}} \geq 0,
$$

where $f i_{\mathrm{E}}$ is the topic rotation and $f i_{\mathrm{R}}$ is the limit rotation.

Reliability density function of vertical displacement and rotation are shown on the next figures.
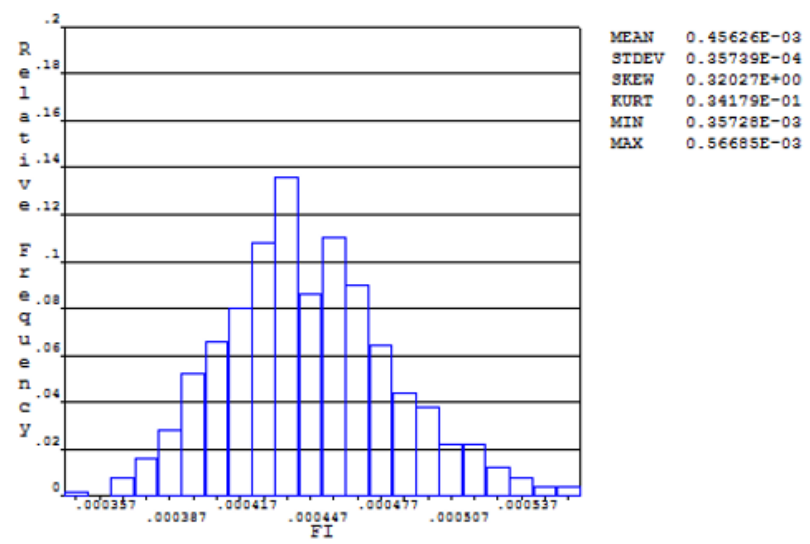

Fig. 5. Reliability density function of rotation.

The results of the sensitivity analysis of the embedded water tank are presented in Fig. 6 , from which it is clear how the individual input parameters affects the output parameter.

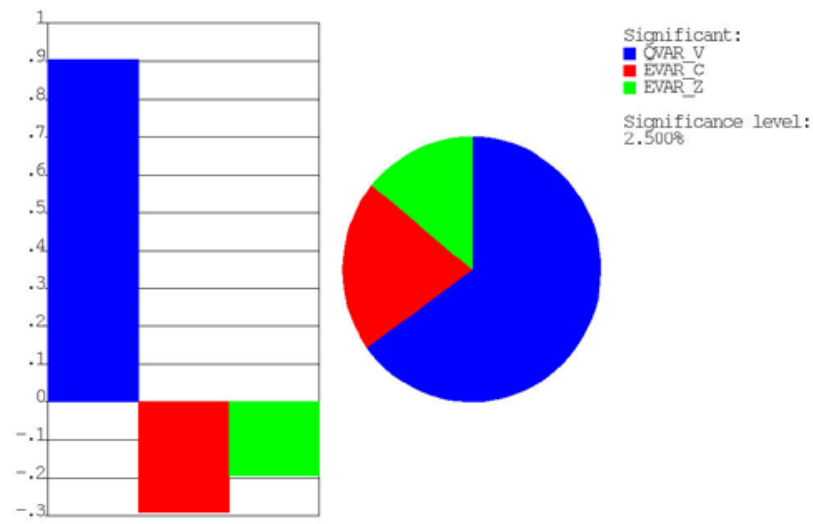

Output Parameter FI

Fig. 6. Sensitivity analysis of the rotation.

The variability of the stiffness of soil and structure and also the variability of loads are important to the rotation of the structure. 


\section{Summary}

In case of deterministic analysis the maximum deflection in the tank footing bottom is $19.73 \mathrm{~mm}$, in the case of probabilistic analysis the maximum deflection is $24.45 \mathrm{~mm}$. Further outputs from probabilistic analysis are given in Tab. 3.

Table 3. Comparison of outputs from deterministic and probabilistic analysis

\begin{tabular}{|c|c|c|c|c|}
\hline \multicolumn{5}{|c|}{ Maximum displacement in tank footing bottom (mm) } \\
\hline Aproach & $\min$ & $\max$ & Mean value & Stand. deviation \\
\hline deterministic & & 19.73 & & \\
\hline probabilistic & 15.912 & 24.447 & 19.775 & 13.983 \\
\hline \multicolumn{5}{|c|}{ Maximum rotation in tank footing bottom x 10-4 } \\
\hline Aproach & min & max & Mean value & Stand. deviation \\
\hline deterministic & & 4.5760 & & \\
\hline probabilistic & 3.572 & 5.6685 & 4.562 & 0.3574 \\
\hline
\end{tabular}

The goal of the probability analysis was to determine the probability of exceeding the deflection limit in the foundation plate and rotation. In case of limit deflection of $20 \mathrm{~mm}$ using 500 Monte Carlo simulations for 15 cycles of the RSM approximation method the probability of failure was equal to 0.41 , in case of limit rotation $5.0 \times 10^{-4}$ given by investor the probability of failure was equal to 0.116 .

The project has been supported by the grant No. 1/0412/18 from Grant Agency of VEGA in Slovak Republic.

\section{References}

1. A. Haldar, S. Mahadevan, Probability, reliability and Statistical Methods in Engineering Design (John Viley\&Sons, New York, 2000).

2. O. C. Zienkiewicz, R.L. Taylor, The Finite Element Method. Volume 2: Solid Mechanics. 5rd ed. (Oxford: BUTTERWORTH-HEINEMANN, 2000).

3. P. Marek, J. Brozzetti J. and M. Gustar M. Probabilistic Assessment of Structures Using Monte Carlo Simulation Background, Exercises and Software, (ITAM CAS, Prague, Czech Republic, 2003).

4. M. Krejsa, J. Kralik, "Probabilistic Computational Methods in Structural Failure Analysis," in Multiscale Modelling 6: (1550006 DOI:http://dx.doi.org/10.1142/ S1756973715500067, 2015).

5. P. Janas, M. Krejsa et al., DOProC-based reliability analysis of structures, in Structural Engineering and Mechanics, Volume 64, Issue 4 (2017).

6. K. Kotrasova, S. Harabinova et al., Numerical Experiment of Fluid - Structure -Soil Interaction, in Procedia Engineering, Volume: 190, (2017).

7. Ansys ${ }^{\circledR}$ User’s Manual, Swanson Analysis Systems, Inc.

8. STN EN 1990 